CODEN : AMMCFL

\title{
STATIC CHARACTERISTIC ANALYSIS OF CONCRETE-FILLED STEEL TUBE TIED ARCH BRIDGE
} Luo Xu

\author{
School of Mechanics and Architectural Engineering, Jinan University, Guangzhou, Guangdong Province \\ *Corresponding author Email: tluoxu@jnu.edu.cn
}

This is an open access article distributed under the Creative Commons Attribution License, which permits unrestricted use, distribution, and reproduction in any medium, provided the original work is properly cited.

\section{ARTICLE DETAILS}

Article History:

Received 10 December 2017

Accepted 08 January 2018

Available online 19 February 2018

\section{ABSTRACT}

Based on a concrete-filled steel tube rigid frame tied arch bridge, the finite element model of the bridge is built with large general structure finite element program ANSYS. Each construction stage will be considered as the real engineering too, so to determine the design tensile force of the tie-bar in all stages. Though comparing the inner force of the arch rib with different arch axis coefficient, the reasonable arch axis shape will be identified finally. At last, stress superposition theory is used to check the stress in the arch rib; the related research results and conclusion can supply experience and practical reference to another homologous tied arch bridge.

\section{KEYWORDS}

concrete-filled steel tube (CFST), tied arch bridge, static characteristic analysis, finite element model

\begin{abstract}
1. INTRODUCTION
Rigid frame tied arch is a new type of bridge appearing in concrete filled steel tubular arch bridges, which is applied wider and wider in recent years. Different from the beam arch composite system, the arch ribs of the rigid frame tied arch bridge and the pier are consolidated without any supports, and the flexible strand is used as a tie bar to balance the thrust of the arch; The tie bar is independent of the bridge deck and does not take part in the force of the bridge deck system, while the bridge deck is a local baring member which have no contribution to the mechanics feature of the whole structure. This kind of structure process both rigid frame structure and tie bar, so it is called as rigid frame tied arch [1,2].
\end{abstract}

The engineering background of this paper is a single span steel tubular arch bridge with a single span $113.7 \mathrm{~m}$, and the width is $32 \mathrm{~m}$. The arch axis is a catenary, and the calculated span is $100 \mathrm{~m}$, the vector height is $20 \mathrm{~m}$ and the vector-span ratio is $1 / 5$. With considering the camber, the arch axis coefficient $m$ is 1.25 , while $m=1.2307$ when the camber isn't considered. The whole bridge is equipped with 2 arch ribs in transverse direction, and the center of the arch is $25 \mathrm{~m}$. Steel arch rib is a welded truss section in fact which was composed of 2 upper and bottom chords (arch foot section of $\Phi 750 \times 16 \mathrm{~mm}$, the middle section of $\Phi 750 \times 12 \mathrm{~mm}$ ), vertical and oblique abdominal rod $(\Phi 300 \times 10 \mathrm{~mm})$ and flat (thickness is $12 \mathrm{~mm}$ ). The arch ribs are transversely provided with a " 1 " type and two "K" type space steel tube truss type wind bracing.

There are 38 cables (19 pairs) with suspension center distance of $5.0 \mathrm{~m}$ in the overall bridge, each of which is made of 15 $\$ 15.24$ strand with epoxy coating protective layer with $1860 \mathrm{MPa}$ standard strength. Each arch rib is equipped with 4 bundle tie bars, and the tie bar adopts high strength and low relaxation prestressed steel strand, every of them is consist of 43Ф15.24 with 1860 standard strength too. The bridge deck is composed of steel cross beams, stiffening steel stringers and " $\pi$ " type carriageway plates and cast-in-place integral layers. The arch abutment are two solid reinforced concrete structures, the cap is $8.2 \times 8.2 \times 4 \mathrm{~m}$ solid reinforced concrete structure. The foundation is consisting of $4 \Phi 2 \mathrm{~m}$ bored piles, with length of $60 \mathrm{~m}$ rock socketed piles. The bridge is shown as figure 1 .

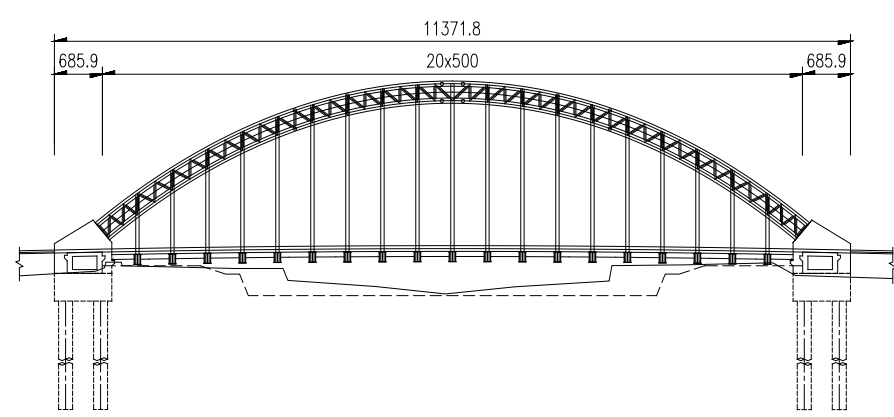

Figure 1: Overall layout of bridge type

The design load for highway -I class, the crowd load is $2.4 \mathrm{kN} / \mathrm{m} 2$, the temperature change according to the structure of the overall $\pm 20^{\circ} \mathrm{C}$, the shrinkage of concrete structure is equivalent to reduce $20^{\circ} \mathrm{C}$; adjust the creep is the additional stress caused by concrete shrinkage and temperature changes, the internal force multiplied by the creep coefficient 0.7 the change of temperature, the creep coefficient of concrete shrinkage force multiplied by 0.45 .

\section{ESTABLISHMENT OF FINITIE ELEMENT ANALYSIS MODEL}

The 3D static mechanic analysis of rigid frame tied arch adopts the general finite element program ANSYS, and the finite element calculation model of the bridge is established according to the design drawing of the construction drawing, as shown in figure 2 [3]. This calculation does not take into account the nonlinear behavior and damage of arch rib, pile caps and foundations. It is assumed that it is always in linear elastic state. According to the " $\mathrm{m}$ " principle, a single pile is regarded as a vertical beam on an elastic foundation (a ground model composed of horizontal springs) to simulate pile-soil interaction. 


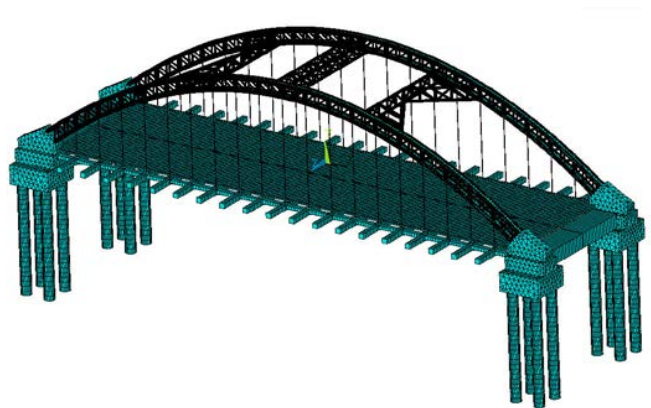

Figure 2: Finite element model of rigid frame tied arch bridge

\subsection{Simulation of Main Arch Rib}

Each string of the arch rib is simulated with double element, namely the upper and bottom chord of steel tube and concrete are simulated by beam elements, the two above analog composite section through a common node. The contribution of the steel tube and the concrete flexural and compressive stiffness to the cross section is considered in this method, but it didn't consider the restriction effect between the two materials, the stiffness formula of CFST members with the method given by literature 1 (shown as formula 1). The arch, chord, belly bar and bracing are simulated by BEAM188 unit (customizable section). The upper and lower leveling is simulated by BEAM4 unit [4].

$$
\begin{aligned}
& E A=E_{c} A_{c}+E_{s} A_{s} \\
& E I=E_{c} I_{c}+E_{s} I_{s}
\end{aligned}
$$

Where:

$E A$ : compressive and tensile stiffness of concrete filled steel tube;

$E I$ : flexural rigidity of concrete filled steel tube;

$E_{c}$ : elastic modulus of concrete;

$A_{c}$ : sectional area of concrete;

$I_{c}$ : bending moment inertia of concrete;

$E_{s}$ : elastic modulus of steel tube;

$A_{s}$ : sectional area of steel tube;

$I_{s}$ : bending moment inertia of steel tube.

\subsection{Simulation of Bridge Deck System}

The bridge deck is composed of steel cross beams, stiffening steel stringers and " $\pi$ " type carriageway plates and cast-in-place integral layers. The steel cross beams, stiffening steel stringers are simulated by 3D beam element Beam4. The " $\pi$ " type carriageway plates is simulated with plate element shell63. The $8 \mathrm{~cm}$ integral thickness and $9 \mathrm{~cm}$ pavement are taken into account when modeling, but the stiffness is not.

\subsection{Simulation of Cable and Tie Rod}

The cable and tied rod are simulated as link element LINK8 in ANSYS, with activating the only pull options. In determining the tension of the tie bar, the EA and EI of the tie bar is set approximate to infinity. When calculating the internal force of the tie bar, the actual rigidity and tensile force of the tie rod are set in ANSYS.

\subsection{Simulation of Abutment and Pile Cap}

The abutment and pile cap are simulated with solid element SOLID45 by coupling the arch of the foot node, the boundary conditions of pile top section, abutment and cap are simulated with coupling the degree of freedom of the adjacent nodes.

\subsection{Simulation of Pile Foundation}

An equivalent soil spring is used to simulate the interaction between the piles and the soil according to " $\mathrm{m}$ " principle, the stiffness of the soil spring is calculated by the " $\mathrm{m}$ " value of the soil medium. The " $\mathrm{m}$ " principle is a common static design method for pile foundation of highway bridge design department in our country which is shown as the following formula:

$$
\begin{aligned}
& K_{1}=\frac{1}{2}\left(m_{1} h_{1}\right) h_{1} b_{1} \\
& K_{2}=\frac{1}{2}\left(m_{1} h_{1}+m_{2} h_{2}+m_{2} h_{1}\right) h_{2} b_{1} \\
& K_{n}=\frac{1}{2}\left(m_{n} \sum_{i=1}^{n-1} h_{i}+m_{n} h_{n}+m_{n} \sum_{i=1}^{n-1} h_{i}\right) h_{n} b_{1}
\end{aligned}
$$

Where, $K_{1}, K_{2} \ldots K_{n}$ : the stiffness of the spring is derived from the ground below each layer; $m_{1}, m_{2} \ldots m_{n}$ : coefficient of proportion of different layers of soil; $b_{1}$ : the calculated width for the pile; $h_{1}, h_{2} \ldots h_{n}$ : thickness of each soil layer.

In ANSYS, the BEAM188 element is used to simulate the pile foundation, and the soil spring is simulated by the COMBIN14 element. The stiffness of the soil spring element is obtained by formula (2).

\subsection{Simulation of Live Load Influence Line Loading}

Because ANSYS did not provide the program automatically according to the specification of the line loading impact function, in order to solve the arch rib of the control section under various loads the most unfavorable stress, internal force and displacement, etc. which require the user to calculate the longitudinal to the control section of the live load influence line position to determine the live load effect of Suspender Force loading range and maximum suspender force.

The method in reference chapter sixth examples, according to the definition of the influence line, in this model, according to a certain loading step (such as $0.5 \mathrm{~m}$ ), along the bridge to the vertical applied from the bridge to the unit concentrated force (the design load of the bridge), and then calculate the displacement control section of the corresponding position [3]. The (deflection), and to the loading position as the abscissa and the corresponding deflection as the vertical coordinate draw curve, this curve is the influence curve of control section.

Once the influence line curve of the control section is obtained, the maximum load response of the control section can be obtained according to the standard Lane load according to the most disadvantageous position on the influence line.

\section{DETERMINE THE DESIGN TENSION OF THE TIE BAR}

The concrete filled steel tubular arch bridge is a self erecting system. Firstly, the arch of the empty steel tube is installed, then the concrete in the pipe is added, then the upper cross beam, the longitudinal beam and so on. Finally, the construction of the bridge deck and railings and other ancillary works are carried out.

The horizontal thrust of rigid frame tied arch is mainly balanced by arch and substructure before the tension of tie bar is taken up. Because of the adverse influence of horizontal displacement on the structure, it is usually required that the lower structure has greater thrust stiffness to bear most of the horizontal thrust.

The arch of concrete-filled steel tubular arch in the early stage of the CFST arch is lighter in weight, and its constant load and horizontal thrust are smaller in general, so can be taken by the lower structure. But since then the constant load, such as beams, stringers, bridge deck pavement and other self weight, so the increase of horizontal thrust should be borne by the tied bar. That is to say, the tie bar should be stretched gradually in batches with the construction of the superstructure. In the actual construction process, the purpose of the tie bar tension is mainly to controls the horizontal displacement of the pier top. The tied bar will be gradually stretched with the increasing constant load according to the tensile force and elongation of the tie bar provided by the design

\subsection{The Design Tension of The Tie Bar}

According to the result of repeated debugging and calculation, the tie bar tension of this bridge is finally divided into six batches as the following:

1) After the erection of arch rib steel tube and pouring bottom pipe concrete arch rib;

2) After the perfusion tube concrete, installation of steel beams;

3) After installing precast " $\pi$ " shaped bridge slab;

4) After cast in place integral layer and bridge slab longitudinal and wet joint;

5) After installing crash walls;

6) After the construction of the pavement.

Table 1: The design tension force of the tie bar 


\begin{tabular}{|c|c|c|c|}
\hline $\begin{array}{c}\text { Construction } \\
\text { Stage }\end{array}$ & $\begin{array}{c}\text { Thrust of Load } \\
(\mathrm{kN})\end{array}$ & $\begin{array}{c}\text { Tension of } \\
\text { Tie Bar }(\mathrm{kN})\end{array}$ & $\begin{array}{c}\text { Unbalanced } \\
\text { Thrust (kN) }\end{array}$ \\
\hline \multirow{2}{*}{1} & 2160 & - & 2160 \\
\cline { 2 - 4 } & -- & -4000 & -1320 \\
\hline \multirow{2}{*}{2} & 2978 & -- & 1658 \\
\cline { 2 - 4 } & -- & -4000 & -1822 \\
\hline \multirow{2}{*}{3} & 2355 & -- & 533 \\
\hline \multirow{2}{*}{4} & -- & -3000 & -2077 \\
\cline { 2 - 4 } & 2432 & -- & 355 \\
\hline \multirow{2}{*}{5} & -- & -3000 & -2255 \\
\cline { 2 - 4 } & 3074 & -- & 818 \\
\hline \multirow{2}{*}{6} & -- & -3000 & -1792 \\
\cline { 2 - 4 } & 2597 & -- & 805 \\
\hline Most Unfavorable \\
Live Load
\end{tabular}

According to the previous design experience, in determining the tension of tie bars at all stages of construction, it is necessary to set the EA value of the tie bar to infinity large and the EI to infinity small.

The cable element LINK10 in ANSYS is used to simulate the tie bar, which does not transmit moment, therefore, only the elastic modulus $\mathrm{E}$ setting for many times (for example 107) of the design value can achieve the above conditions. According to the axial force of each stage of the dead and live load analysis results of tied units, combined with the actual situation of the arch bridge and considering the anti push ability to determine construction phase of each batch of tied design tension, as shown in Table 1. The results show that the maximum theoretical thrust of the structure in each stage of the construction is $2255 \mathrm{kN}$.

\subsection{The Checking Calculation of Tie Force and Horizontal Displacement of Pile Top}

The first, second batch of tie bar design tension is $4000 \mathrm{kN}$, Third, fourth, fifth and six design tensile force are all $3000 \mathrm{kN}$. The total tension of the tie bar is $20000 \mathrm{kN}$, the tied bar of each arch rib is consisting of 4 bunches tendons, the area of every tendon is $6.02 \times 10-3 \mathrm{~m} 2$, the maximum tensile force of each tie rod is $5000 \mathrm{kN}$, and the maximum design stress of tie bar is $830.6 \mathrm{MPa}$.

The stress of the prestressed tie bar is similar to that of the cable stayed bridge. Therefore, the checked calculation of the tie bar can be carried out according to the design calculation method of the cable in cable-stayed bridge, in which allowable stress of cables $[\sigma] \leq 0.4 \mathrm{Rb}$, the safety factor $\mathrm{f}=$ $\mathrm{Rb} / \sigma \geq 2.5$, among them, $[\sigma]$ : allowable stress of cables, $\mathrm{Rb}:$ the tensile standard strength of cables, especially in this paper is $1860 \mathrm{MPa}, \sigma:$ the maximum tensile stress of cables.

According to the above checking calculation method, the safety factor of the tie cable of this bridge is:

$$
f=1860 / 830.6=2.24
$$

Since the tie bar is a general mechanic component, the stress amplitude caused by dead load and live load is usually small; in addition, because the tie is not suspended in the air, there is no problem of wind-induced vibration, the safety coefficient of cable tied limit can be relaxed properly (the safety factor in actual engineering is controlled within 2.2).

According to the calculation results under the above conditions, the maximum horizontal displacement of the pile top appears in the first stage (after the erection of arch rib steel tube and pouring bottom pipe concrete arch rib), The maximum horizontal displacement of the pile head isumax $=4.6 \mathrm{~mm}<5 \mathrm{~mm}$, which satisfies the requirement that the maximum value of the foundation displacement (should not exceed $6 \mathrm{~mm}$ ) in the relevant codes.

\section{DETERMINATION OF COEFFICIENT OF ARCH AXIS}

The shape of arch axis will directly influence the distribution and magnitude of internal force of arch rib section. For through concrete filled steel tube rigid frame arch bridge deck system, the arch axis line type selection should be two times parabola or lower catenary arch axis coefficient [5]. In the process of determining the arch axis, the classic "five-point method" is applied [6].

bending moments of the controlling section more evenly distributed (for example the vault and arch foot section) under constant loads, let the arch rib stress distribution more reasonable.

The following models are calculated respectively for arch shaft coefficients $\mathrm{m}$ equal to $1,1.25,1.5,1.75,2,2.25$, respectively, and the calculated bending moments of each control section are shown in Table

Table 2: The dead load bending moment of each control section with different arch axis coefficients $(\mathrm{kN} \cdot \mathrm{m})$

\begin{tabular}{|c|c|c|c|c|c|}
\hline $\begin{array}{c}\text { Arch Axis } \\
\text { Coefficient }\end{array}$ & $\begin{array}{c}\text { Arch Foot } \\
\text { Section }\end{array}$ & $\mathrm{L} / 8$ & $\mathrm{~L} / 4$ & $3 \mathrm{~L} / 8$ & Vault \\
\hline 2.25 & -1249 & -8571 & -771 & 7018 & 10573 \\
\hline 2 & -2035 & -7511 & -450 & 6197 & 9321 \\
\hline 1.75 & -2927 & -6370 & -1253 & 5324 & 7978 \\
\hline 1.5 & -3937 & -5141 & -594 & 4392 & 6530 \\
\hline 1.25 & -5105 & -3815 & 159 & 3397 & 4958 \\
\hline 1 & -6459 & -2361 & 1420 & 2320 & 3242 \\
\hline
\end{tabular}

According to Table 2 data, with the increase of arch axis coefficient, the negative moment (absolute value) in arch foot section decreases, the positive moment of arch vault increases, the negative moment in $\mathrm{L} / 8$ increases, the positive moment of $3 \mathrm{~L} / 8$ section is increased, which meet with the moment change regular of tied arch bridge in related theory. When $\mathrm{m}=1.25$ (without considering camber), the dead load moment absolute value in the arch foot is nearly equal to that of the vault, the other control section of the absolute value is relatively small, therefore, this is determined as the final design arch axis (the catenary with $m=1.25$ ) of the bridge.

\section{STRESS CALCULATION OF ARCH RIB}

\subsection{Stress Superposition Method and Internal Force Superposition Method}

The steel tube concrete arch bridge adopts the self erecting construction method, and the main arch rib is formed gradually, so the mechanic feature of each part is different. There are two different methods for strength checking: the stress superposition method and the internal force superposition method, there are very different in calculation results of these two methods.

The stress superposition method takes into account the cross-section characteristics and load conditions of the arch ribs at each stage of the formation process, and their internal forces are calculated respectively. Then, the stress superposition method is superimposed on the corresponding fiber at the section. While in the internal force superposition law, the cumulative stress history is without considering, the current stress state is direct calculated with all the load stage and the current section characteristic. Therefore, it is more reasonable to use stress superposition method to check the stress.

\subsection{Stress Checking}

According to the pouring sequence of concrete in steel tube, the application of stress superposition calculation mainly includes three types of section characteristics in the relating construction stages: empty steel tube section; the hollow steel tube in upper chord and concrete filled steel tube in lower chord section, concrete filled steel tube section. According to the construction sequence and live load condition, it is divided into 21 stages, and stress superposition method is applied to calculate the stress of the arch string. The stress of the arch string is shown in Table 3.

Table 3: The maximum combined stress of arch rib

\begin{tabular}{|c|c|c|c|c|c|}
\hline Section & Arch Foot & $\mathrm{L} / 8$ & $\mathrm{~L} / 4$ & $3 \mathrm{~L} / 8$ & Vault \\
\hline Steel tube & -129.5 & -102.1 & -113.2 & -97.6 & -128.8 \\
\hline concrete & -15.2 & -11.3 & -13.7 & -11.5 & -15.9 \\
\hline
\end{tabular}

Note: the stress unit is MPa, the compression is negative while tensile is positive.

According to the calculation results, both the arch rib and the concrete in the pipe do not appear tensile stress, and the maximum compressive stress of the arch rib meets the requirements of the code. 


\section{CONCLUSIONS}

(1) This paper is based on the engineering background of a rigid frame tied arch bridge, according to the design experience and the existing research results, the rigid frame tied arch finite element static analysis model is established with the application of ANSYS software, which will provide reference for similar bridge engineering finite element analysis.

(2) Through the finite element analysis results, with the horizontal displacement of the pile top not exceeding the limit value as the control target, after repeated adjustment calculation, the design tension of the tie rod in each construction stage is determined finally.

(3) The catenary arch shaft is fitted by the classical "five-point weight method", and the internal forces of the arch ribs with different arch coefficients are compared and analyzed. Based on above analysis results, the reasonable arch axis of the rigid tied arch is determined.

(4) According to the principle of stress superposition, the stress in each stage of the arch rib construction is calculated and superposed. Based on the calculation results, the stress of the rigid frame tied arch bridge meets the requirements of the code. The related research results and conclusion can supply experience and practical reference to another homologous tied arch bridge.

\section{REFERENCES}

[1] Baochun, C. 2007. Concrete-filled steel tube arch bridge (Second Edition). [M]. Beijing: China Communications Press.

[2] Baochun, C. 1999. The design and construction of concrete-filled steel tube arch bridge.[M]. Beijing: China Communications Press.

[3] Liming, Z. 2003. Application methods and examples in Bridge Engineering with Algor Programme and Ansysis Programme. [M]. Beijing: China Communications Press.

[4] CECS. 1990. China Association for standardization of engineering construction. Specification for design and construction of concrete filled steel tubular structures (CECS 28:90). [M]. Beijing: China planning publishing house.

[5] Wei, P., Yunfeng, C., Shigui, D. 1999. Optimum design of half through concrete filled steel tubular arch bridge. [J]. Chinese Journal of highway engineering, (S1).

[6] Lingsen, Y. 1984. Bridge engineering. [M]. Beijing: China Communications Press. 